\title{
perifèria
}

Número 20 (1), juny 2015

www.periferia.name

\section{Entrevista a Joan Francesc Mira: els inicis de I'Antropologia al País Valencià}

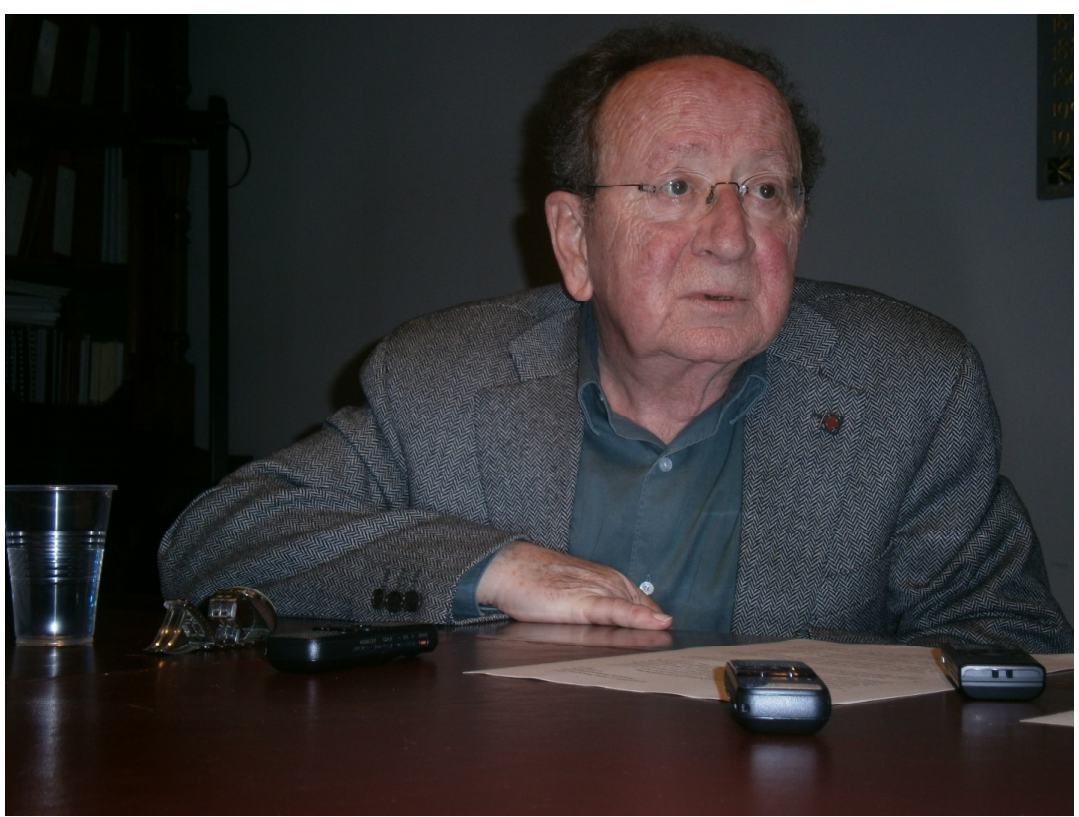

Joan Francesc Mira, durant l'entrevista (Foto: Montserrat Clua i Fainé)

Autores: Gemma Costa, Júlia Morros i Júlia Pagès

Directora: Montserrat Clua Fainé- Universitat Autònoma de Barcelona

DOI: http://dx.doi.org/10.5565/rev/periferia.463

\section{Resum}

En aquesta ocasió el Projecte Entrevistes ha tingut el privilegi d'entrevistar un intel-lectual de primera fila en l'àmbit lingüístic català, el Dr. Joan Francesc Mira, distingit amb el Premi d'Honor de les Lletres Catalanes (2004), la Creu de Sant Jordi (1991) i membre de I'Institut d'Estudis Catalans des de 1999. Àmpliament conegut com a escriptor de novel-les i contes, com a traductor de textos clàssics (com els Evangelis, la Divina Comèdia o l'Odissea) i com a assagista i col-laborador habitual en diversos mitjans de premsa, potser és menys conegut en la seva vessant com a antropòleg. L'entrevista es va realitzar a Barcelona el 3 d'abril de 


\section{perifèria}

Número 20 (1), juny 2015

www.periferia.name

$2014,{ }^{2}$ poc després que aparegués publicada la seva darrera narració El tramvia groc, on recull les experiències de la seva infantesa a la pedania de La Torre de València durant la dècada del 1940 i 1950. Amb un to proper i divertit, Mira ens explica com va entrar l'antropologia en la seva vida i el paper fonamental que ell va tenir en la instauració de la disciplina en el País Valencià i en la creació del Museu Valencià d'Etnologia.

Paraules clau: Joan Francesc Mira, Antropologia, País Valencià, Museu Valencià d'Etnologia.

\section{Resumen}

En esta ocasión el Projecte Entrevistes ha tenido el privilegio de entrevistar a un intelectual de primera categoría en el ámbito lingüístico catalán, el Dr. Joan Francesc Mira, distinguido con el Premio de Honor de las Letras Catalanas (2004), la Creu de Sant Jordi (1991) y miembro del Institut d'Estudis Catalans desde 1999. Sobradamente conocido como escritor de novelas y cuentos, como traductor de textos clásicos (como los Evangelios, la Divina Comedia o la Odisea), y como ensayista i colaborador habitual del semanario valenciano El Temps, quizás es menos conocida su vertiente como antropólogo. La entrevista se realizó en Barcelona el 3 de abril de $2014,{ }^{3}$ poco después de que se publicara su última narración, El tramvia groc, donde recoge sus experiencias infantiles en la pedanía de La Torre de Valencia durante la década de 1940 y 1950. Con un estilo cercano y divertido, Mira nos explica como entró en la antropología y el papel fundamental que él tuvo en la instauración de la disciplina en Valencia y en la creación del Museo Valencano de Etnología.

Palabras clave: Joan Francesc Mira, Antropología, País Valencià, Museu Valencià d'Etnologia.

Pregunta: Bon dia i moltes gràcies per atendre'ns. Volíem començar dient-li que quan ens vam documentar per preparar aquesta entrevista vam veure que li havien fet moltes entrevistes per la seva part literària, però a nosaltres ens interessa endinsar-nos en la part de la seva biografia vinculada amb el món de l'antropologia i del què vostè ha treballat. Així que, si li sembla bé, el primer que li volíem

2 Volem agrir la generosa disposició del CERC (Centre d'Estudis i Recursos Culturals de la Diputació de Barcelona), que ens va cedir la seva Sala Noble per fer l'entrevista.

3 Agradecemos la generosa disposición del CERC (Centre d’Estudis i Recursos Culturals de la Diputació de Barcelona), que nos cedió su Sala Noble para la realización de la 'entrevista. 


\section{perifèria}

Número 20 (1), juny 2015

www.periferia.name

preguntar és sobre els seus orígens com a antropòleg. Sabem que vostè va estudiar Filosofia i Lletres a la Universitat de València...

Joan Francesc Mira: A veure, comencem fent un parèntesi. Jo realment on vaig estudiar Filosofia seriosament va ser a Roma, a la Universitat Gregoriana. A València vaig estudiar assignatures d'Història d'Espanya i Literatura Espanyola per convalidar el títol que tenia d'Itàlia de Llicenciat en Filosofia. O siga que jo, realment, estudiar a la Universitat de València no he estudiat. He aprovat assignatures i els exàmens que havia de fer per convalidar aquell títol. Ara, sí que hi vaig estar present en uns anys - els anys 61-63- que van ser uns anys de molta efervescència, per dir-ho d'alguna manera. Eren anys de córrer davant la poli, de molts crits i de tantes coses que ara ja semblen molt ingènues o molt curioses. Perquè d'allò fa molts anys i resulta difícil imaginar ara quines eren les condicions en aquell moment, oi? Però era divertit...

\section{P: Als anys seixanta i setanta l'antropologia al País Valencià i en} general a I'Estat Espanyol no es coneixia gaire. La nostra pregunta és: vostè com coneix o s'endinsa en aquesta disciplina?

J.F. Mira: Bé, he de començar amb una explicació prèvia perquè si no realment no s'entén com van anar les coses. Com sap tothom perfectament i sobretot els que sou del gremi, als anys 60 l'antropologia social (o cultural, com vulgueu) a l'Estat

"A través del Carmelo vaig conèixer l'Esteva Fabregat $i$ les primeres reunions del grup de gent que feia antropologia"

Espanyol pràcticament no existia. Hi havia alguna persona aquí, els de Barcelona que feien alguna cosa amb el senyor Esteva, a Madrid... En fi, no res. I jo vaig arribar a l'antropologia d'una manera absolutament de rebot. Jo, com que venia (i vinc) de la filosofia, el que m'interessava era 


\section{perifèria}

Número 20 (1), juny 2015

www.periferia.name

bàsicament l'antropologia filosòfica.

Jo vaig passar dos estius a Alemanya, treballant tot l'estiu. Primer per conèixer el país i practicar la llengua, i després per fer allò que en aquella època ingènuament en dèiem "experiència obrera": treballar en una fàbrica metal-lúrgica pura i dura. Resultat: que allà ja havia llegit alguna cosa de

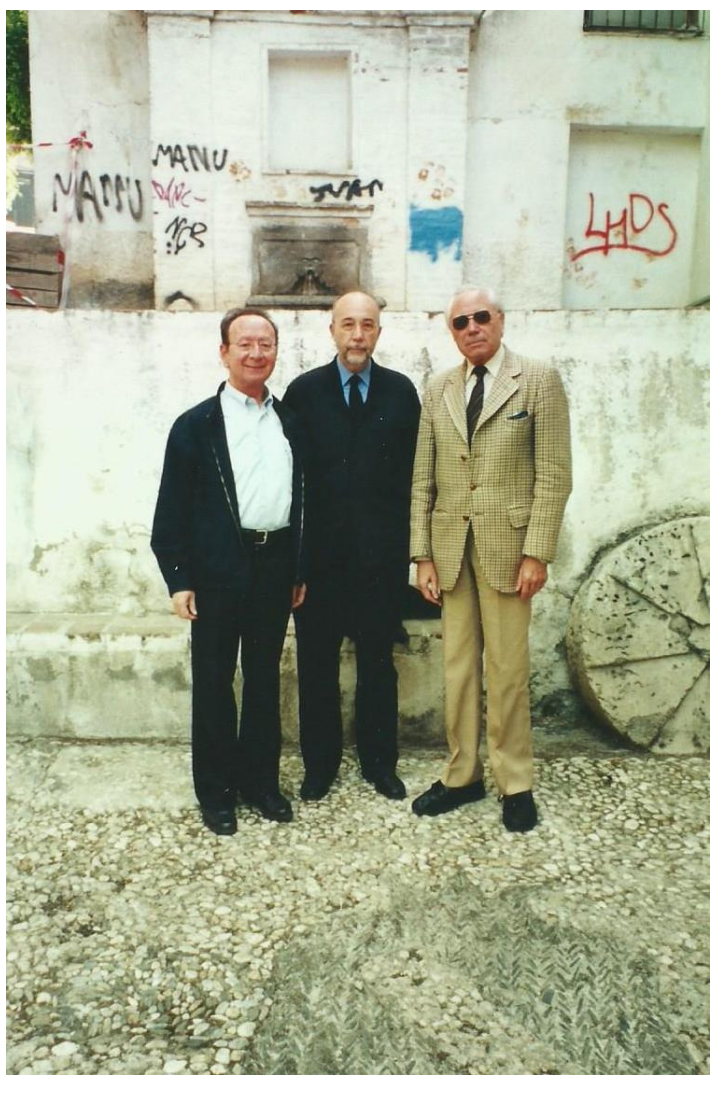

D'esquerra a dreta: Joan Francesc Mira, Ricard Sanmartín i Carmelo Lisón (Foto cedida per Mira)
Marx i m'interessava l'antropologia filosòfica, el concepte de I'home en les obres de joventut de Marx (les més filosòfiques, les anteriors a $E I$ Capital). I bé, vaig comprar-me tot un volum de textos de Marx dels anys 1840 i em vaig posar a estudiar allò. Era molt interessant però era una cosa purament d'antropologia filosòfica. I llavors jo volia fer una tesi de Ilicenciatura, la tesina, justament sobre aquell concepte: el concepte antropològic-filosòfic de l'home en les obres de joventut de Marx. Me'n vaig anar al catedràtic d'Ėtica i Sociologia de la Facultat de Filosofia a València, que resulta que era un pare dominicà, el Padre Todolí. I quan jo hi vaig anar i li vaig plantejar la cosa, "Mire vostè, que jo voldria fer una tesina sobre això i sobre..." em va contestar: "Dónde va! Fuera! Fuera de aquí!" Així, tal qual. 


\section{perifèria}

Número 20 (1), juny 2015

www.periferia.name

${ }^{4}$ Bé, jo anava llegint en alemany (ja que n'havia après, tot i que després I'he oblidat en gran part). Anava llegint i dic: "Hosti, aquí hi ha moltes coses que jo no puc vore clares a partir només d'un enfocament filosòfic. Deu haver-hi alguna altra cosa." I llavors vaig començar a furgar i a mirar.

I vaig començar a trobar obres d'antropologia social o antropologia cultural bàsicament. Algunes obres franceses: vaig comprar des de manuals de Ciències Socials fins a llibres de Lévi-Strauss, de Durkheim i companyia. I després els anglesos. I finalment em vaig dir: "I ara jo què faré?". Podia fer poquetes coses: anar-me'n a París a buscar algú o anar-me'n a Òxford. I me'n vaig anar a Òxford i vaig conèixer John Beattie. I em va dir "Mira, per cert, aquí acaba de doctorar-se un estudiant que hem tingut molts anys aquí, espanyol, que és un tio molt interessant, que val molt, que ha publicat un llibre, que ha fet un dels primers estudis etnogràfics a España (o quasi, perquè ja havia llegit alguna cosa de Pitt Rivers, People of the Sierra) $i$ mira, ací tens l'adreça...". I era Carmelo Lisón. Llavors vaig anar a Madrid a conèixer-lo. Pobre Carmelo Lisón, també acabava d'arribar i no tenia on caure mort. En realitat anava fent classe per aquí i per allà, coses d'història d'Amèrica, d'antropologia americana i no sé què. I bé, així vaig començar amb l'antropologia

Agraïm de tot cor a Joan Francesc Mira que ens cedís aquesta fotografia juntament a la que mostrem més endavant, on se'l veu conversant amb Jim Fernández. 


\section{perifèria}

Número 20 (1), juny 2015

www.periferia.name

A través del Carmelo vaig conèixer l'Esteva Fabregat i les primeres reunions del grup de gent que feia antropologia: al voltant del Lisón a Madrid, i aquí a Barcelona al voltant de l'Esteva Fabregat. D'una manera o altra vam començar a posar-nos en relació i per aquí vam començar. Evidentment en aquell moment no podien existir - ni per mi ni per ningú - uns inicis en antropologia per la via acadèmica regular perquè aquesta via no existia. I per tant això meu van ser una sèrie de rebots circumstancials: de la filosofia hegeliana i companyia a l'antropologia filosòfica de Marx; botar d'aquí a

“(...) un dia a les 8 del matí sona el telèfon, l'agafa la meua dona i ve i diu: " $E l$

telèfon, de part del professor Lévi-Strauss”.
I'altra antropologia passant per Durkheim o Marcel Mauss, anar a Òxford i conèixer John Beattie i algú més. Ara no puc recordar qui rondava per allí dels grans clàssics. Estic parlant de la dècada dels anys seixanta. Ja deu fer cinquanta anys, mare de déu senyor!

I per aquí va començar la cosa. Vaig trobar, per aquestes circumstàncies, el que en podríem dir el nucli embrionari de tota l'antropologia que s'ha fet després. De fet, de tota aquella colla que rodàvem, jo diria que $10 \circ 15$ pràcticament tots eren catedràtics o professors d'antropologia. Excepte jo, que em dedicava al grec: era catedràtic de grec i em guanyava la vida ja com a professor de grec. Primer com a catedràtic d'institut i després a la universitat. I bé, pocs anys després jo vaig fer el meu primer estudi de camp - la tesi- i després ja vaig estar en relació amb els grups de París al voltant de Lévi-Strauss, en projectes mig de sociologia rural i mig d'antropologia social o etnologia. En fi, aquestes coses que et fan una certa impressió, que un dia a les 8 del matí sona el telèfon, l'agafa la meua dona i ve i diu: "El telèfon, de part del professor Lévi-Strauss". Uauu! És com si et 


\section{perifèria}

Número 20 (1), juny 2015

www.periferia.name

telefona el Papa, no?! I era una pura xamba! Resulta que Lévi-Strauss estava organitzant un grup de treball sobre evolució de les estructures de parentiu en les comunitats rurals a Europa, i va reunir un grupet de gent de diferents llocs de l'Est i de l'Oest per fer un equip. Vam estar a París molt de temps, però també a Hongria, a Oslo, a Viena... I aquí vaig començar tot un conjunt de relacions que a finals dels anys 70 em van portar a Princeton, amb en Jim Fernández, que en allò que anomenem antropologia expressiva o antropologia simbòlica, per mi és el number one. James Fernández

"Quan pocs anys després venia algú nou, un aprenent, a parlar amb mi (...) el primer que jo li deia era: 'Tst! Primer un metre!

Un metre de llibres, eh?

Quan t'hages llegit un metre de llibres, tornes $\mathrm{i}$ continuem parlant."”
McClintock, és nebot d'asturians. Ell, després d'haver treballat durant molt de temps a Gabon i a la Guinea, amb els Fang i altres grups, ha dedicat molts anys a Astúries, amb els pastors de la muntanya. I quan vaig haver de decidir si em quedava allà a Princeton, a fer allò que es diu carrera acadèmica més 0 menys internacional, o me'n tornava a casa a fer el que em donava la gana amb la vida, vaig optar per la segona possibilitat.

\section{P: Per tant, quan vostè comença a fer d'antropòleg, el panorama europeu i espanyol de la disciplina en aquells moments com era?}

J.F. Mira: El panorama espanyol, tal com us he dit, era un panorama que com a tal no existia. Eren uns inicis molt puntuals, molt embrionaris, al voltant de determinades persones: al voltant d'una determinada persona a Madrid i d'una altra persona a Barcelona. I punto. Hi ha una cosa que és molt important i és si tens una tradició o no la tens. Per a totes les coses, eh? Per a l'antropologia i per a les matemàtiques, I'astronomia o la biologia molecular. I en antropologia aquesta tradició no existia. Com s'havia de fer 


\section{perifèria}

Número 20 (1), juny 2015

www.periferia.name

llavors?

Jo ja tenia una feina de catedràtic de grec i no m'havia de guanyar la vida amb l'antropologia i això em deixava molt de temps i molta llibertat. Però quina era la manera de començar en un cas com el meu (però que no vaig ser l'únic)? Llegint molt: llibres, llibres, llibres... I subratllar llibres, prendre notes, fer-se notes. O siga, adquirir aquella formació, diríem teòrica, per tu mateix. De tant en tant consultant alguna cosa amb en Carmelo Lisón, amb qui tenia més confiança personal. Però bàsicament fent allò que fa molts anys que ja no està de moda, que és estudiar. Allò que ara està tan desacreditat, no? Ara tothom quan ha de fer un treball agafa l'internet... No, no! Mira, estudiar implica agafar un totxo així [separa les dues mans uns 50 centímetres] de 500 pàgines, te l'agafes i pim-pam, pim-pam, pimpam, te'l llegeixes fins al final. I després quan pocs anys després venia algú nou, un aprenent, a parlar amb mi i em deia: "Mira, que m'interessaria això, començar per..." El primer que jo li deia era: "Tst! Primer un metre! Un metre de llibres, eh? Quan t'hages llegit un metre de llibres, tornes $i$ continuem parlant." [Riures]

Jo vaig haver de fer-me el meu metre o dos metres de llibres amb tot el que anava comprant, ja que afortunadament dominava tres o quatre llengües (per les circumstàncies personals que m'han portat a viure per aquí i per allà). Això era la primera cosa. A partir d'ací, més o menys orientat per tots els manuals d'estudis de camp i etc., més tot el que havia llegit ja del que podríem dir antropologia social del Mediterrani, amb tot aquell bagatge vaig començar els meus primers treballs de camp. I d'ací va sortir el meu primer llibre que bàsicament fou la meitat de la meva tesi doctoral. ${ }^{5}$

5 Es refereix al Ilibre Un estudi d'antropologia social al País Valencià: Vallalta i Miralcamp (1974), la primera etnografia publicada en català. 


\section{perifèria}

Número 20 (1), juny 2015

www.periferia.name

\section{P: I quines van ser les seves principals influències? Ha parlat de Carmelo Lisón.}

J.F. Mira: Sí, Carmelo Lisón en gran part perquè havia fet ja el tipus de treball - la clàssica monografia d'una comunitat rural -, que era I'única cosa que nosaltres podíem fer. Perquè per aquesta falta de tradició i per falta d'institucions amb una línia d'estudis en aquest sentit, era impensable que un antropòleg jove que comença se n'anés a estudiar a Gabon, els Papús de Nova Guinea, els Bororos o el que fos, no? No podia ser de cap manera. Per tant, com que no podia ser, doncs ni t'ho plantejaves. Per tant, a la majoria ens ha tocat de fer el que diríem una espècie d'antropologia de proximitat. Feies allò que materialment podies fer. Maria Càtedra se n'anava a Astúries amb els pasiegos, Teresa San Román amb el gitanos, Isidoro Moreno amb els andalusos... Feies allò que podies seguir. Vol dir que bàsicament la tècnica i tot el bagatge teòric que necessitaves eren la tècnica i el bagatge dels estudis de comunitat rural. No podíem fer una altra cosa. Per tant no hem tingut aquesta tradició que tenien els britànics, els francesos, els holandesos fins i tot, o els nordamericans, de poder estudiar allò que diríem, entre cometes, "societats exòtiques", en el sentit grec de la paraula: que estan fora. I per aquí havíem de començar. Després ja podies teoritzar, o traure unes conclusions, o fer estudis comparatius o fer mil coses, no? Però havies de començar per aquí.

Pensa que, si no estic equivocat, a banda de coses que són d'un altre tipus que havia fet Julio Caro Baroja, la primera monografia d'una comunitat rural a Espanya, el primer estudi en aquest sector clàssic és el de Pitt Rivers, The people of the Sierra, de I'any 1954. I el del Carmelo Lisón, Belmonte de los 


\section{perifèria}

Número 20 (1), juny 2015

www.periferia.name

Caballeros $^{6}$, és dels anys 60. És la seua tesi, que acabava de vindre d'Òxford amb el llibre sota el braç. A partir d'aquí vaig començar a fer coses una mica més teòriques sobre idees de cultura mediterrània, sobre sistemes de parentiu, coses publicades a París. I a part hi havia totes aquelles reunions que fèiem a París o a Viena, tot això més o menys beneït 0 patrocinat per don Claudi; no don Claudi Esteva, sinó don Claude LéviStrauss, des de l'École Pratique des Hautes Études (EPHE). Va ser de les primeres vegades que vam fer un estudi combinat de països de l'Est i de I'Oest. Venia gent d'Hongria, de Polònia i del que era llavors Txecoslovàquia, la meitat amb els guardes de la KGB al darrere... Sí, sí! Amb la parella, perquè jo he tingut col-legues txecs que venien de Praga i portaven un comissari polític aquí [es refereix a l'esquena, com un guardaespatlles]. Poca broma, eh, era una cosa terrible! I bé, a Noruega vam estar-hi també. Anàvem fent. I llavors el que adquiries era una experiència, diríem, de les diferents maneres d'enfocar les coses en diferents llocs, diferents països i procedències, al costat dels polonesos, dels xecs, dels eslovacs, dels noruecs, dels suecs i dels holandesos... I això va ser molt interessant. No sé si es continua fent, em sembla que no. Només lamente no haver acceptat la invitació de la professora Tatiana Zaslávskaia (que després va ser la gran sociòloga de la perestroika), que em convidava a Novosibirsk, a la cèlebre Akademogorodok.

P: Com acaba de dir vostè, va estar treballant amb Claude LéviStrauss. I ens agradaria saber en quin tipus de projecte treballaven, i sobretot, què li va aportar treballar amb Lévi-Strauss?

\footnotetext{
6 Es refereix a Belmonte de los Caballeros. Anthropology and History in an Aragonese Community, publicat per Oxford University Press el 1966.
} 


\section{perifèria}

Número 20 (1), juny 2015

www.periferia.name

J.F. Mira: Bé, Lévi-Strauss ens donava unes orientacions generals. Ens reunia de tant en tant i donava la benedicció al grup. A ell bàsicament el que li interessava, al principi, eren les adaptacions i canvis de les estructures de parentiu. I jo vaig fer uns estudis que després es van publicar a París i a Holanda justament sobre això. Per exemple: com diferents estructures de parentiu condicionades per una situació territorial (territorial en el sentit físic, no de distinció de la propietat) i per una estructura social i econòmica, sent de tipus diferents, es podien adaptar per a produir resultats equivalents. Feies aquell tipus de perspectiva estructural funcionava. Com per exemple, dins d'un sistema d'herència que en principi és de distribució igualitària (perquè el dret històric valencià - que era com el de Catalunya, amb hereu preferent- el va

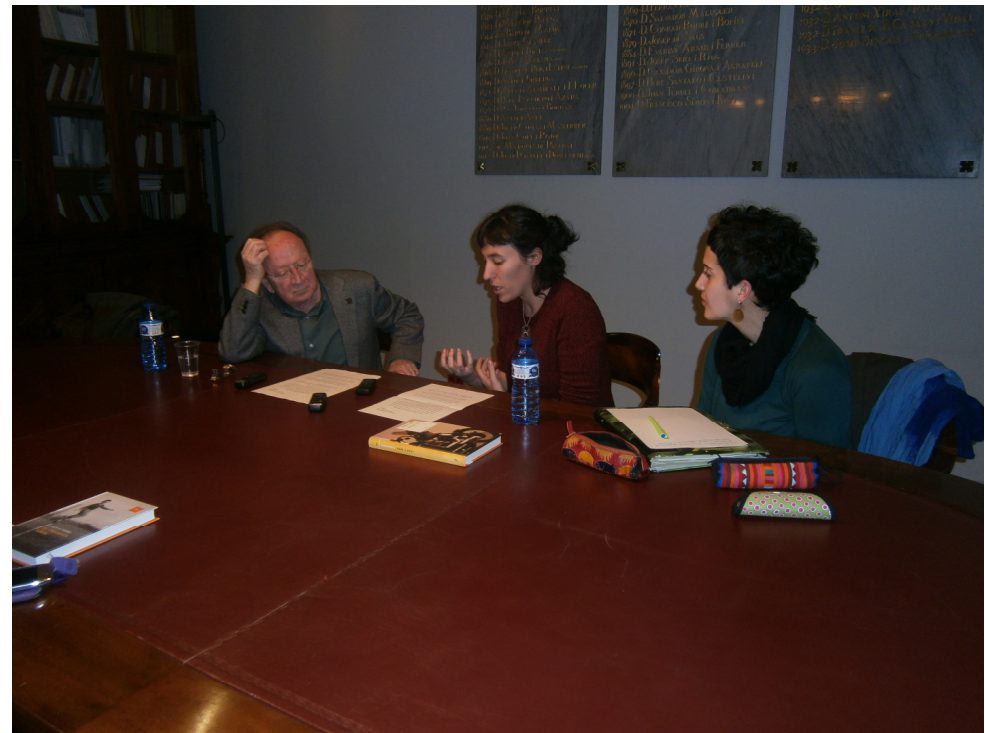

Joan Francesc Mira a la dreta, amb Júlia Pagès i Gemma Costa, dues de les entrevistadores (Foto: Montserrat Clua i Fainé)

suprimir Felip V), hi ha tota una sèrie d'adaptacions que fan que el resultat final - que és el mantindre la integritat dels patrimonis, és a dir dels llinatges - funcione igualment, quan l'estructura del lligam de patrimoni i llinatge teòricament no existeix. Això era molt bonic. 


\section{perifèria}

Número 20 (1), juny 2015

www.periferia.name

Una altra línia d'estudi van ser anàlisis comparatives sobre com es poden ajustar o com es varen ajustar aquestes comunitats rurals tradicionals a tot el procés de modernització. Des del punt de vista purament econòmic, des del punt de vista de les comunicacions i des del punt de vista d'una cosa molt bonica que era l'estructura de les festes. I vaig fer uns estudis que eren sobre aquesta adaptació. Per exemple les festes que després han estat tant desacreditades - amb motiu, perquè després s'han desbordat, s'han convertit en un disbarat -, dels bous de carrer, d'aquells famosos bous embolats. Allò originàriament era una cosa que tenia un valor simbòlic per al conjunt d'una petita comunitat rural. Pensa que llavors la gent (jo estic parlant de finals dels 60) no era com ara, que si s'ha de fer una festa s'omple qualsevol poble de gent i tot són cotxes! Llavors quasi ningú tenia cotxe. Per tant, els que participaven a la festa eren fonamentalment la gent del mateix poble. La festa era un reflex de l'estructura interna. El protagonisme i l'organització mateixa de la festa tenia tot un valor molt emblemàtic, molt representatiu, del conjunt del sistema ètic i de valors i d'organització de la mateixa comunitat. Bé, vaig estar uns anys treballant en això i... I després d'això deu ser quan vaig anar a Princeton, ja no sé, fa molts anys.

\section{P: S'identifica amb...}

J.F. Mira: No. No m'identifique amb res.

\section{P: Anàvem a preguntar-li si s'identificava amb algun corrent antropològic concret.}

J.F. Mira: No, perquè realment, siga pel que siga..., des del moment en que no hi ha escoles i tu no t'has fet la teua primera formació acadèmica dins d'una escola, doncs fas la teua pròpia, fas el teu propi còctel. O siga que en els meus primers sis o set anys de lectures, jo podria dir que he 


\section{perifèria}

Número 20 (1), juny 2015

www.periferia.name

llegit, en percentatge, un volum equivalent d'antropologia francesa d'una certa tradició (des de Durkheim fins a Lévi-Strauss o els que vénen després, com Jean Cuisenier o Isac Chiva, amb qui vaig tindre tracte) i d'antropologia britànica (els clàssics també, Radcliffe-Brown, EvansPritchard and company) i antropologia americana. I els hauré llegit en proporcions més o menys equivalents, tant els manuals com de monografies. A casa tinc una petita biblioteca; tot i que fa molts anys que he deixat pràcticament de comprar llibres d'antropologia perquè m'he anat distanciant més o menys de l'antropologia i de les revistes a què estava subscrit molts anys com Current Anthropology. Però crec que les meues lectures dels primers anys estarien en una proporció equivalent. Conec la tradició de l'antropologia francesa, que és molt especial en el tipus d'origen: en definitiva procedeix de tota la tradició de la sociologia científica, de Comte, Marcel Mauss i de

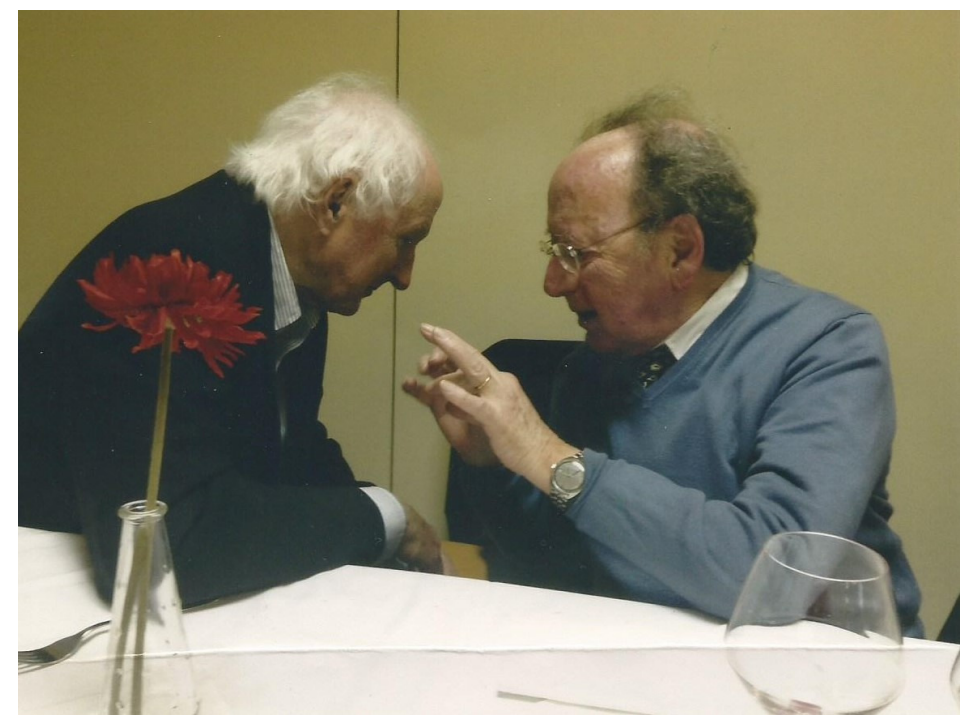

Jim Fernández i Joan Francesc Mira (Foto cedida per Mira) la tradició historiogràfica francesa dels Annales en conjunt. L'antropologia britànica, per exemple, no té ni remotament tanta relació amb la perspectiva històrica. I clar, els britànics també estudien un tipus de societats en un determinat tipus de condicions: bàsicament societats colonials que estaven encara en ple funcionament d'una manera bastant activa. Quan per exemple, ara fa poc, veus en la premsa el que està passant al Sudan del Sud... i recordes que tens a casa les monografies clàssiques dels Dinka i 


\section{perifèria}

Número 20 (1), juny 2015

www.periferia.name

dels Nuer! T'agafa un mal al cor...

I I'antropologia nord-americana que té també uns altres orígens... Està dins d'una tradició de sociologia molt més empírica, molt menys teòrica i molt més experimental, per dir-ho d'alguna manera. Amb moltes connotacions psicològiques, també de la tradició de l'empirisme psicològic americà. I que està feta en un tipus de societats que estan com si diguéssem paralitzades, és a dir, semicongelades. Existeixen encara en conjunt, el que diríem com un totum, com el famós complex whole, però estan com mig congelades en el temps. En definitiva, tot plegat són perspectives diferents i si veniu a casa i veieu la meva biblioteca trobareu que hi ha una mica de tot.

O siga que no, no puc parlar de cap línia ni de cap corrent determinat. Segurament si als vint anys hagués tingut la possibilitat d'anar a estudiar antropologia a París o a Òxford, llavors diria que jo vaig a estudiar a Òxford amb tal i tal, amb l'escola de la línia d'Evans-Pritchard o de Radcliffe-Brown, o de qui siga... O si hagués anat a Chicago, que allí hi havia Sol Tax i després la seva filla, la Susan Tax, que va ser molt amiga meva i més endavant em va convidar a Chicago a donar unes conferències. Podria haver estudiat allà; però no és el cas. Cada un està posicionat per la seva pròpia circumstància. Cosa de la qual, a més, estic molt satisfet: de no haver sigut part d'una escola o d'una sola tradició. Per altra banda, també seria molt bonic haver tingut una escola $\mathrm{i}$ uns mentors: has tingut una gent que pertany a una tradició d'estudis, una tradició d'anàlisi, de tot un bagatge conceptual i metodològic... I et trobes, com si diguérem, en una família, no? Però bé, com que, per força, jo he anat de llanero solitario tota la vida, doncs... què hi farem! No és ni mèrit meu ni culpa meua, eh?

P: Al 1974 va publicar el seu primer estudi, que és un estudi d'antropologia de Vallalta i Miralcamp. Nosaltres ens preguntàvem: com definiria vostè l'etnografia que va fer al País Valencià? Com a 


\section{perifèria}

Número 20 (1), juny 2015

www.periferia.name

\section{auto-etnografia o com a antropologia at home?}

J.F. Mira: I per què voleu una definició? Per què voleu posar etiquetes a les coses? Això vos han ensenyat a l'escola? A tot voleu posar etiquetes! [riures] M'és igual, poseu-li el nom que preferiu: antropologia de proximitat, antropologia circumstancial i antropologia de fer el que pots. Sí, perquè el que manen són les circumstàncies. I ja he dit abans que té els seus avantatges i té els seus inconvenients. L'avantatge és perquè de vegades I'antropologia té un obstacle difícil: que és que participar i conviure amb una població d'una societat totalment, radicalment, rigorosament distant, pot crear justament un abisme entremig, que per molta voluntat que hi poses no l'arribes a trencar, no l'arribes a superar.

Jo recorde un estiu que vaig passar a Zimbabwe amb un missioner que portava allí quaranta anys i havia fet la primera traducció de la Bíblia en nàmbia. Hi vaig anar amb la meua filla, entre altres coses per veure els animals i uns parcs impressionants. Quan anàvem amb aquell bon home, el missioner coneixia de prop tota la gent, i tots se l'estimaven, el coneixien, i a més parlava perfectament la llengua... i la meitat de les coses ell no les entenia i portava quaranta anys allí! I tenia una caixa així de gran, plena de notes de camp, era impressionant! I quan havia de traduir conceptes de la Bíblia a la llengua d'allà, després de viure allà tants anys, de vegades no s'aclaria. I un dia ens presenta el cap de la tribu. Tu t'imagines un cap de la tribu, tens una imatge d'un cap de la tribu. El cap de la tribu era un home que estava assegut en una cadira mig desballestada, amb uns pantalons curts tots esparracats i una jaqueta damunt que estava tota apedaçada. Això sí, amb la guàrdia personal darrera. Tenia dos paios darrere que anaven igual de mal vestits que ell... I de sobte et trobes això i dius: jo aquí puc estar-me deu anys i no ho entendré això! Amb aquella imatge, amb aquella pinta que tenia, doncs el respectaven igualment. I clar, amb tot el 


\section{perifèria}

Número 20 (1), juny 2015

www.periferia.name

que has estudiat sobre l'aspecte extern, la parafernàlia de l'autoritat... És igual tot això. De sobte, arriba un punt a la setmana o als quinze dies d'estar allí que... bum! Se te'n va tot a baix. O siga que el treballar sobre una societat molt distant és complicat. I la prova és que les grans monografies clàssiques són d'antropòlegs que s'han estat anys, i anys, i anys, i han tornat d'Òxford al camp, i han tornat una altra vegada i una altra...

Per altra banda treballar amb el què jo en dic una antropologia de proximitat (proximitat territorial, cultural, o el que siga), també té la pega que és molt difícil justament aconseguir la perspectiva. Una antropologia té la dificultat d'entrar-hi; I'altra té la dificultat de sortir-ne. Has de sortir d'allà, i fer com si tu no ets un d'ells, com si tu tot això no ho saps, o tot això no has d'interpretar-ho el primer dia. Abans d'interpretar una cosa amb els paràmetres que tu ja portes subconscientment has de dir: Eeep! Quieto parao! Para allí, continua mirant, continua parlant i continua amb la gent, continua comparant i al final a veure què passa.

Montse Clua: Amb el que ha explicat de que la seva formació va ser feta amb lectures perquè no hi havia massa més com fer-ho, em pregunto com ho va fer per enfrontar-se amb la dificultat del treball pràctic, si li va costar fer el treball de camp. Perquè almenys amb el grau d'ara els estudiants fan un simulacre de treball de camp, se'ls ensenyen les tècniques, tenen uns tutors que els ajuden... etc. Però una persona que està sola, que s'ho ha fet tot amb lectures, quan es troba al camp realment, al moment de fer l'etnografia...

J.F. Mira: Prèviament jo $\mathrm{m}^{\prime}$ havia llegit els meus manuals sobre treball de camp, els "Notes and Queries" i els manuals clàssics que tothom se'ls hauria d'estudiar. Et puc assegurar que el $90 \%$ dels llicenciats actuals en sociologia, etc., no en tenen ni punyetera idea perquè no s'han estudiat els 


\section{perifèria}

Número 20 (1), juny 2015

www.periferia.name

manuals. Tu t'imagines un químic al laboratori abans d'estudiar el manual de química? No, primer t’has d'estudiar els manuals i després ja es debuta. A mi això em va vindre molt bé perquè ja m'havia llegit els manuals que encara tinc per casa subratllats i anotats, com els Méthodes des sciences sociales de Maurice Duverger, els manuals de treball de camp d'antropologia i de sociologia (i de sociologia rural), abans d'anar al camp. I mentre llegia ja m'anava imaginant fent el treball de camp: i això com ho aconseguiria? I això? Jo portava ja tot un aparell de conceptes de mètode: de mètode de treball de camp, d'aprofitament del treball de camp, de disciplina en el treball de camp i d'escepticisme en el treball de camp. És a dir: no et cregues tot el que veus, no et cregues tot el que et diuen. El primer que has de fer quan et diuen una cosa és no creure-te-la. Perquè en determinat tipus de societats on vas, com les primeres que jo vaig estudiar (poblets de muntanya petits), si m'hagués de creure tot el que m'estava dient aquella gent estava completament perdut! I ja van els pobres aprenents, o els sociòlegs que fan enquestes, i es creuen tot el que els diuen i ho apunten. En les enquestes, per exemple, d'un treball de camp de sociologia hi ha una cosa increïble, el parany en què tots cauen. I és que el moment més important d'una enquesta o d'un treball de camp és el moment del contacte de l'enquestador i l'enquestat, o del preguntador i el que respon. Si tu aquell moment no el controles, si no tens ja una certa reserva i vas apuntant tot el que et diuen, pot aparèixer qualsevol cosa després. Si és un tipus de societat, diguem, que tu la controles, molt més homogènia (i fins i tot així, eh!), per exemple, de sub-societats com les comunitats rurals més o menys aïllades i clàssiques - com el món dels masos -, és una cosa impressionant. Ells t'enganyen per definició; i forma part del joc enganyar-te, home! És el típic masover que va a comprar. Un dia baixa al poble i vol comprar, no sé..., un martell. I s'està mitja hora primer fent-li creure al botiguer que li interessa qualsevol cosa excepte el 


\section{perifèria}

Número 20 (1), juny 2015

www.periferia.name

martell. O és quan t'expliquen històries $\mathrm{i}$ aquestes històries la gent se les inventa. Tu te la creus o no te la creus. No t'has de creure totes les històries, això és un principi fonamental. Has d'estar molt segur de per què te I'han contat, per què te la conten adornada d'aquella manera, per què et contesten a tu quan fas una pregunta, per què et contesten sí o no, blanc o negre... Per què t'estan contestant blanc quan en realitat tu ja sabies o sabràs després, que és negre o que és gris. Allí està la gràcia. Ara, us he de dir una cosa, eh?, "Ells t'enganyen per que supose que tampoc no us expliquen a les definició; iforma part facultats: això té una part de mètode de ciència i té una part també artística i estètica, a diferència de la sociologia habitual.

del joc enganyar-te,

home!"

\section{P: Tal i com ens ha dit, va estar fa un temps a Princeton i quan va tornar va haver de triar entre la seva carrera antropològica o quedar-se al País Valencià. Què és el què el va fer triar tornar a Espanya?}

J.F. Mira: Realment vaig tornar perquè ja havia triat, vaig tenir un llarg debat amb la meua dona [riu]. És que això de Princeton és el paradís dels paradisos. Princeton és una universitat molt peculiar, una universitat del nivell de Harvard o de Yale però amb deu vegades menys d'estudiants. Allí només entren 1.000 nous estudiants cada any i només hi ha 4.000 undergraduate i 1.000 graduats i punt. És una universitat amb un nombre d'alumnes tan petit i el primer dia que vas a la biblioteca (et parle dels anys 78 i 79) i et trobes una biblioteca de cinc milions d'exemplars que tenia tres-cents empleats... I, com a cada professor que volia, em van assignar el meu cubicle o despatxet privat, dins de la biblioteca (a més del despatx al departament), per a tindre els llibres que m'interessaven... I és clar estava al.lucinat. En fi. 


\section{perifèria}

Número 20 (1), juny 2015

www.periferia.name

\section{P: I què és el que va fer tornar?}

J.F. Mira: Em va fer pànic allò que en diem el cursus acadèmic. Perquè m'hauria tocat fer-me responsable d'una sèrie de coses. Si em quedava allà ja sabia el que m'esperava: més faena. Jo vaig estar dirigint juntament amb el cap de departament el seminari departamental sobre l'origen i l'evolució de les cultures mediterrànies, des dels grecs fins ara. Vaig fer coses de comparacions molt boniques. Per exemple,

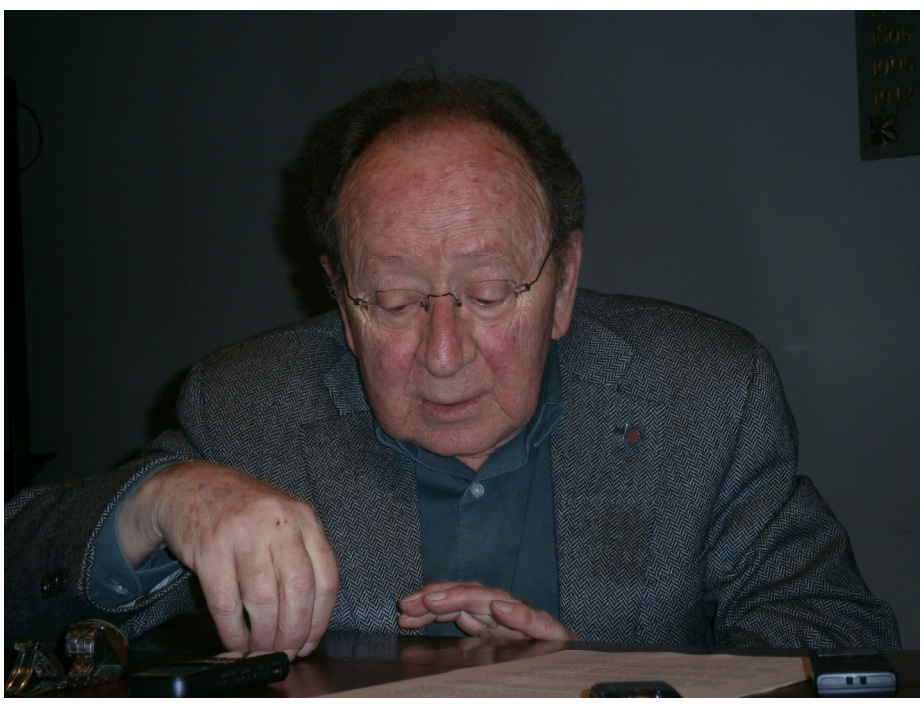

Joan Francesc Mira, en un moment de l'entrevista (Foto: Montserrat Clua i Fainé)

llegir textos d'Hesíode, Els Treballs $i$ els Dies, que és del segle VII o VIII a.C. i comparar-ho amb monografies antropològiques del anys 50 o $60 \ldots$ I era fantàstic! Anaves mirant, anaves mirant... i era impressionant! I amb aquesta perspectiva històrica, tenint una certa base de cultura clàssica o de llegir grec com jo he tingut (i que he acabat traduint l'Odissea, que és molt més divertit) i amb aquesta perspectiva antropològica, podia combinar les dues coses. De fet, sobre això vaig escriure un article llarg: "De com es pot ser grec per trenta segles". Jo tenia aquí una orientació d'una cosa que hauria fet, hauria fet alguna cosa més del que he fet després. I al mateix temps vaig començar a interessar-me sobre els temes al voltant de la cultura nacional, sobre la teoria de la cultura nacional, la formació i evolució de les nacions... I és clar, allà hi havia tota la bibliografia que a Espanya no trobaves enlloc. Amb l'avantatge que tenies totes les facilitats del món per a 


\section{perifèria}

Número 20 (1), juny 2015

www.periferia.name

buscar el llibre, comprar-lo, fotocopiar-lo... Era una cosa... allò era el paradís.

I llavors em vaig haver de plantejar: em quedo aquí o torne allà al meu país, desgraciat, putejat [riu], on tot està per fer? Bé, encara vaig fer un acte - diguem de servei públic- al tornar, que va ser crear el Museu d'Etnologia de València. Que va ser una aventura purament personal, sense cap suport, pràcticament sense diners... Buf! Una cosa que algun dia hauria d'escriure'n una novel-la! Vaig crear el museu veient al mateix temps com a la "izquierda de lujo", als "socialistas obreros españoles", l'únic que els interessava era l'art contemporani, és a dir l'art de les elits. I es van gastar en el museu d'art contemporani cent vegades més que en el museu d'etnologia, on hi havia tota la cultura popular material. No els interessava en absolut; es creien tots molt fins, molt moderns i molt intel-lectuals [riu]. Em vaig barallar amb tots i me'n vaig anar a casa.

\section{P: Seguint amb el tema del museu etnològic de València, ens agradaria que ens expliqués una mica com va ser la seva experiència i si considera que es va tenir en compte el seu projecte.}

J.F. Mira: Jo mai li vaig dir museu etnològic. Igual que els museus de prehistòria no es diuen museus prehistòrics, ni els museus d'art no es diuen museu artístic, ni museu escultòric ni museu pictòric. Jo li dic museu d'etnologia. Després li han posat el nom de Museu Etnològic, clar, i ja m'han fotut! No han entès res! Jo tenia tot un projecte que no es va tindre en compte per res. Es van trobar amb un treball fet pràcticament gratis, pràcticament gratis! Per quatre duros, per l'equivalent del que serien ara dos-cents o tres-cents mil euros, van tindre cinc mil objectes adquirits, netejats, posats en condicions, catalogats, classificats i organitzats i exhibits en cinc o sis sales restaurades. A base de què? De sacrificar-se un grupet de persones, entre les quals la meua súper amiga Josepa Cucó i de treballar 


\section{perifèria}

Número 20 (1), juny 2015

www.periferia.name

pràcticament sense cap retribució. I de que en aquell moment el president de la diputació tenia una perfecta confiança amb mi i no vaig haver de passar per traves burocràtiques ni per res, o siga que això va permetre una agilitat i un estalvi increïbles. Clar, jo venia d'Estats Units, sabia com es feien les coses allà. I, o se'n fien de tu o no se'n fien. Si es refien de tu, tu ves fent lliurement, i si no es refien de tu, no et busquen, no t'accepten. Doncs així va anar, eh?

Curiosament l'edifici originalment tenia la mateixa funció que aquest on estem ara, ${ }^{7}$ que era la beneficència. Quan vam entrar allà encara quedaven uns pocs asilats vells, algunes criatures $\mathrm{i}$ algunes monges. I el que havien sigut cinc o sis sales, els dormitoris i tot plegat, ho vam netejar, ho vam pintar i ho vam arreglar. I d'una manera purament improvisada vam inaugurar el museu. Hi havia el president de la Generalitat valenciana i el Conseller de Cultura. I van inaugurar i vam obrir. I jo tenia tot un projecte d'haver fet allà un centre de l'estil -modestament - del que s'ha inaugurat fa poc a Marsella. Un museu que hagués estat també un centre educatiu. I de fet els primers mesos que jo estava allà venien les escoles. Hi havia tots els museus que jo havia vist a Oslo, Copenhaguen, París, Holanda, Alemanya, Àustria... M'havia fet una tournée de museus europeus d'antropologia o de cultura popular. I clar, als països civilitzats d'Europa això s'ho prenen en serio. Però els ignorants dels socialistes es pensaven que això era una cosa "d'atrasaos" i l'únic que avui tenia importància era l'art contemporani. Tu et posaves allà, et gastaves... què es van gastar? Jo vaig gastar quaranta milions per muntar el museu, ells se'n van gastar quatre mil pel d'art contemporani. O siga d'un a cent. Això era el que

\footnotetext{
7 Es refereix a l'antiga Casa de la Caritat, que és on està el CERC i la sala on es va fer I'entrevista.
} 


\section{perifèria}

Número 20 (1), juny 2015

www.periferia.name

atorgaven a I'"elegància intel-lectual" de l'art contemporani, que està molt bé però..., tot allò que és la creativitat popular, diríem, de generacions en generacions, materialitzada en objectes, això els importa només un $1 \%$ de l'art contemporani. Era així, deixem-ho córrer. Així el vam fer.

\section{P: Nosaltres venim de la Universitat Autònoma de Barcelona i estem} fent el Grau d'Antropologia Social i Cultural. Sabem que a la Universitat de Barcelona també n'hi ha i a la Universitat Rovira i Virgili de Tarragona. Informant-nos ens vam adonar que a la Universitat de València no existeix el Grau d'Antropologia com existeix aquí a Catalunya. Què en pensa?

J.F. Mira: Bé, la poca antropologia que hi ha a València és gràcies a la Josepa Cucó. Es podia haver quedat a València - però no es va quedar i va fer molt bé - el Ricard Santmartín, que procedia del dret. Ell tenia una formació en dret molt interessant amb un gran jurista que era molt amic nostre. I aquell home, el seu mestre, tenia una perspectiva històrica i tenia interès per una estructura jurídica molt peculiar que és la dels pescadors de

"La poca antropologia que hi ha a València és gràcies a la Josepa Cucó." I'Albufera, que tenen un sistema jurídic intern antiquíssim i molt curiós. I va enviar Ricard Santmartín a fer una tesis sobre això, que va veure que calia una visió antropològivca, i vingué a buscar-me a mi. I jo li vaig dir, ho recordo perfectament: "Ricard, si vols una perspectiva antropològica, comença per llegir un metre de llibres mínim, eh?". Ho va fer, va tornar i li dic: "Ara si, comencem". I llavors li vaig presentar a Carmelo Lisón i companyia. I finalment doncs, en comptes d'anar-me'n jo a Madrid se'n va anar ell. I llavors la Josepa Cucó, que havia fet història a València i el seu germà era el meu amic (ha sigut el meu més gran amic I'Alfons Cucó, un gran historiador i un gran polític), vingué a parlar amb mi. 


\section{perifèria}

Número 20 (1), juny 2015

www.periferia.name

Jo li vaig presentar alguns col-legues de París que ja coneixia de temps i va entrar a fer antropologia a París, amb tot aquell grup. Tornà a València i li vaig dir: "Pepa, et toca a tu; el que jo no vaig fer, tu estàs en condicions de fer-ho". I allí ha estat batallant, fins que ha aconseguit simplement un forat per a I'Antropologia. I com que la Facultat on ella està és de Sociologia i Antropologia Social, en realitat és la ruta per fer Antropologia. Perquè, és clar, gairebé totes les carreres, fins i tot en Filologia Anglesa fan alguna assignatura de sociologia, també a econòmiques, i per ací alguns estudiants arriben a I'Antropologia Social... Però en fi, ha sigut gràcies a ella. Però no sé si hi més possibilitats...

També hi ha I'Associació Valenciana d'Antropologia, un grup de gent bona i molt interessant, que han tingut la gentilesa de crear un premi d'investigació amb el meu nom, pobre de mi. En tot cas, molta gent d'aquell grup, dirigits per ella, s'han centrat més en antropologia urbana. A la Josepa li vaig dirigir jo en la pràctica - no acadèmicament però si personalment - la tesi. Després ja es va dedicar més a l'antropologia urbana. Va estar uns anys també fent treballs molts interessants a Portugal, Lisboa i a Madrid sobre la continuïtat, la pervivència, d'aquests nuclis diríem del radicalisme marxista de bona voluntat. No els clàssics sinó d'aquells que s'han quedat encara, que continuen mantenint una espècie d'idealisme. Sobre això ha escrit coses molt boniques.

\section{P: Sabem que vostè té interès pel tema de la cultura valenciana, la nació i la identitat. Ens preguntàvem quin és el context social i polític en què a vostè li sorgeixen tots aquests interessos.}

J.F. Mira: Aquí hauríem de distingir entre el que puga ser la meua actitud "La història contemporània d'Europa, la dels segles $X I X i X X$, sense la història dels nacionalismes, dels com a ciutadà, amb aquella terminologia que ara sembla que ja no la gasteu del "ciutadà moviments nacionals europeus, no es 


\section{perifèria}

Número 20 (1), juny 2015

www.periferia.name

compromès". Aquesta societat és la meua, m'ha tocat, mala sort. Hauria preferit que fos qualsevol altra, eh? Que no estiga tant plena de punyeteries i de limitacions i de problemes. I per tant, m'he ocupat d'intentar entendre no ho he aconseguit encara - aquest tipus de problemes, buits o desastres de la pròpia societat valenciana. Potser que ha derivat d'això, no ho sé, però potser deriva que a Princeton vaig trobar una bibliografia extraordinària, que ací no la coneixia ningú, sobre el tema d'història dels nacionalismes europeus. La història contemporània d'Europa, la dels segles XIX i XX, sense la història dels nacionalismes, dels moviments nacionals europeus, no es pot entendre, en contra del que diuen la quantitat d'ignorants, des del Ministre Margallo a intel-lectuals i líders polítics espanyols de dreta i d'esquerra..., que diuen uns disbarats enormes, com ara que nacionalisme i Europa són contradictoris...! Si justament Europa s'ha fet a base dels moviments nacionalistes! Si no s'hagués fet això, si no hi hagués hagut quantitat de moviments nacionalistes, sabeu què passaria? Que només hi hauria I'Imperi Austrohongarès, I'Imperi Alemany, I'Imperi Rus, I'Imperi Otomà i França. Hi hauria quatre imperis, i aquella cosa estranya que també és una mena d'imperi que és França. A Europa hi ha 30 - 35 estats que són producte el $80 \%$, 8 de cada 10, de moviments nacionalistes, d'un tipus o d'un altre. Cada un té les seves condicions, cada societat evoluciona d'una manera. Però també hi ha uns certs factors comuns i conceptes que poden servir per a explicar això. Hi ha una cosa molt curiosa, quan estudies una mica això dels moviments nacionalistes. Jo vaig fer un llibre que es deia Crítica de la Nació Pura, ${ }^{8}$ fent una mica d'ironia del llibre de Kant de Crítica de la Raó Pura. No em diga vostè que primer cal definir què és una nació, perquè és com intentar definir què és 


\section{perifèria}

Número 20 (1), juny 2015

www.periferia.name

una societat o què és una família! I escolta, de famílies n'hi ha de moltes classes, de societats $n$ 'hi ha de moltes classes, etc. I moviments nacionals $i$ nacionalistes $\mathrm{n}$ 'hi ha de moltes classes també. Hi ha una sèrie d'elements comuns, elements que depenen de determinades circumstàncies, internes 0 externes, històriques o territorials. Uns són productes, per exemple, d'una reacció o una evolució a partir d'una experiència colonial; altres a partir d'una experiència de les monarquies expansives europees, des de final de l'edat mitjana fins al segle XIX, i cada una amb unes circumstàncies. Però hi ha unes maneres d'entendre-ho. Has d'elaborar uns criteris analítics. A base de què? A base de llegir molta bibliografia, a base de llegir molts llibres. Si vols entendre quin ha sigut el moviment dels txecs, els eslovacs o els croats has de llegir-te bons manuals de la història de I'Imperi Austrohongarès per saber com funcionava, de com funcionava la política (la política cultural, la política econòmica i la política administrativa i estructural) en allò que era I'Imperi Austrohongarès. Si no saps, per exemple, que durant molt de temps el Regne d'Hongria dominava al seu torn els croats i els eslovacs, tampoc no pots entendre res! S'ha de saber història. S'han de saber unes quantes coses per a entendre una poqueta cosa. I d'allí, doncs, em vaig interessar pel tema, que és apassionant quan el mires sense prejudicis, eh?

Bé, m’han passat coses molt curioses. Jo en el llibre aquell que és del 1984, vaig elaborar una sèrie de conceptes (i inclús de terminologia), que després com a gran novetat han aparegut en els llibres d'Anthony Smith i d'altres. I aquí resulta que tothom cita a Anthony Smith, i cita no sé qui i no sé cuantos. I tu dius... jo, deu anys abans d'aquest llibre, això ja ho havia dit! Mire vostè aquesta pàgina, que quan no ho havia dit ningú, això ja ho havia dit jo. Per què? Perquè vaig tenir la xamba de controlar una bibliografia molt àmplia i jo tinc una miqueta de coco, per anar pensant i cavil.lant. Jo ara ja m'ho prenc amb bon humor, perquè... amb els col-legues nostres de 


\section{perifèria}

Número 20 (1), juny 2015

www.periferia.name

per aquí bé ho sabem: aquests senyors, que com que han publicat en anglès i en una editorial britànica o nord americana, els ha conegut tothom. Ara resulta que un llegeix el llibre d'aquell bon home, Benedict Anderson, i descobreix que les nacions són "comunitat imaginades"! Punyeta, si jo ja ho havia explicat fa 30 anys, exactament així! O que les nacions són processos evolutius i no entitats fixades... Això ho vaig dir fa 30 anys. Ara resulta que ho llegeixen en un llibre traduït de l'anglès i tothom el cita! [riures] En fi, paciència. Si aquell Ilibre meu, Crítica de la Nació Pura, I'hagués editat en anglès a Oxford University Press 0 si m'hagués quedat dos anys més a Princeton, això s'editava a la Princeton University Press i

"Què vol dir d'esquerres? seria una autoritat mundial. Però bueno, és Òbviament, en cada igual. La pròxima vegada naixerem a Holanda moment vol dir una cosa i la cosa funcionarà millor [riu].

diferent."

\section{P: Vostè ha tingut molta implicació política...}

J.F. Mira: Implicació política, la justeta. Mira, jo he estat militant, més actiu o menys, però militant d'allò que en cada moment representava, un... diguem-li nacionalisme, diguem-li patriotisme, és igual: progressista, d'esquerres. Què vol dir d'esquerres? Òbviament, en cada moment vol dir una cosa diferent. Perquè no és el mateix les tonteries que teníem al cap els anys 60 i principis dels 70, fantasies sobre revolució i la "dictadura del proletariat"... El proletariat està molt a gust a casa i no té ganes de revolució. I menys ara, que a França per exemple el proletariat vota massivament Le Pen. El primer partit obrer de França des de fa 20 anys és el del Le Pen. Sí! Això són mapes i xifres, eh! Jo, que a banda d'això, sóc un viciós de la informació, des de fa 30 o 40 anys estic subscrit al Times i al Nouvel Observateur. I fa vora d'uns 20 anys, en unes eleccions franceses, 


\section{perifèria}

Número 20 (1), juny 2015

www.periferia.name

mirant Le Nouvel Observateur, hi havia uns mapes per circumscripcions i per departaments, que com són molt petits són molt detallades. I mirant, mirant, vaig pensar: aquí passa alguna cosa rara. Mirant, m’agafo l'evolució del vot comunista, m'agafo la fulla del vot del Front Nacional de Le Pen, vaig posar la fulla al vidre de la finestra, una al damunt de l'altre, i placa! Clavat! En fi, és un altre tema. Un altre dia em feu una entrevista de tres hores sobre això i us ho explicaré. No us cregueu cap titular dels diaris! Els diaris espanyols no tenen ni idea del que passa a França ni del que passa a Itàlia aquests dies. El corresponsal d'El País a Itàlia no sap ni italià. Diu unes bestieses, unes coses que dius: "Pero qué dice este chico?". I el de França, es mira Le Monde per damunt, i va xerrant coses vulgars.

\section{P. La nostra pregunta era com I'antropologia I'ha ajudat en la seva carrera política?}

J.F. Mira: De cap manera. En la meua carrera política... en la meua inexistent carrera política $\mathrm{m}$ 'ha tocat donar la cara un parell de vegades per opcions totalment suïcides, per petits partits d'esquerra nacional. Quan em vaig presentar en algun Iloc era perquè em deien "Ei tu, posa la cara", però eren coses purament suïcides i per tant no tenen més importància. No, no hi he trobat mai cap relació. Si de cas... en allò que en podríem dir carrera per dir-ho d'alguna manera - literària, potser a l'hora d'escriure sobre determinats passatges o escenes en alguna de les meues novel-les, la capacitat d'observació, de relació i de penetració que tens per l'experiència directe i també per les lectures com a antropòleg, sí que et dóna una certa capacitat de percepció. Percepció de les escenes, de les persones, de les relacions, etc., que la pots transmetre al camp de la literatura. Jo tinc algun paper escrit d'algun congresillo d'alguna cosa sobre antropologia i literatura. Com a mínim un parell de treballs sobre el tema de la relació entre I'antropologia i la literatura. Que també és un tema molt interessant. De fet, 


\section{perifèria}

Número 20 (1), juny 2015

www.periferia.name

hi ha qui diu "Com es nota que eres antropòleg". Si tu no ho sapigueres, no ho notaries! [riu] En tot cas ho note jo. El lector que no ho sap, si a mi em llegeix algú sense saber qui sóc, sabrà que sóc un escriptor i prou. Si no té cap notícia del que jo he fet en el camp de l'antropologia, no se li acudiria pensar de relacionar-ho. És una certa capacitat que vas desenrollant. Ara, també el Nostre Senyor, per la divina providència o per l'esperit absolut de Hegel, t'ha d'haver donat unes certes qualitats, perquè si no les tens és inútil per molt que t'hi encaparres. Jo per exemple, podria estudiar música, anar al conservatori, i no hi hauria res a fer. "És que jo vull ser cantant d'òpera". "Mire vostè, Nostro Senyor no I'ha triat per aquest camí". [riu]

Doncs el mateix: "Jo vull ser antropòleg!" "Mira, fill meu, no serveixes."[riures] Sí o no, poca broma. Això no és el mateix que l'economia o el que siga, o la sociologia de l'enquesta i els percentatges. L'antropologia té aquesta part d'ingredient personal, que és una ciència però també és un art. I el que val, val, i el que no, no val. El que val potser que no ho aprofita, però si el que no val intenta aprofitar-ho... no se'n surt. És el mateix que si algú volguera ser cantant. No podria. Per molta vocació que tingues, si no tens oïda i no tens veu, no podràs. Doncs n'hi ha més d'un que es pensa que és antropòleg i es posa a treballar i... tio, no ho has entès perquè no serveixes! I és així. No, no, no és broma. S'ha de servir per alguna cosa, per la pintura, per la literatura, per la poesia, pel que siga. Jo per exemple, els versos que faria serien malíssims. Jo no puc ser poeta. Puc ser discretament un bon narrador, però poeta no podria. Són coses que no sé com fer-les. Això pareix una collonada, una barbaritat, però és real. Determinades activitats requereixen unes determinades qualitats. Que tu les treballes, les aprofites, les explotes, les cultives i això donarà fruit. Però si no les tens, no. Voldria parlar de la relació que ha tingut una cosa amb I'altre. Però en l'àmbit de la meua, podríem dir, inexistent carrera política 


\section{perifèria}

Número 20 (1), juny 2015

www.periferia.name

pública, no n'hi ha cap, cap.

\section{P: I pensàvem també en l'àmbit educatiu, com que vas ser professor...}

J.F. Mira: No. Perquè és una cosa paral-lela. Vull dir, el treball que jo he fet en aquesta vida, durant molts anys, per interès, per dedicació i per vocació és l'antropologia, però mai he tingut cap relació amb l'antropologia com a professió formal remunerada. I el que he ensenyat tota la vida, que és grec, però en aquesta matèria, a què $\mathrm{m}^{\prime}$ he dedicat teòricament, mai he tingut un interès real com a filòleg.

A mi el que m'ha interessat ha estat ensenyar grec perquè em guanyava la vida bastant còmodament, fent poquetes classes cada dia, tranquil, amb pocs alumnes i sense conflictes (que no és el mateix que impartir classes de teoria econòmica en una facultat d'econòmiques!). Ensenyar grec és una cosa de poques classes, poca gent, poca faena. Que, ni en els 18-20 anys que vaig estar a l'institut, ni els 20 anys a la universitat ensenyant grec no he volgut tenir mai cap càrrec de cap tipus. A mi que no em veiés ningú. Jo he fet les meues classes, he fet les coses ben fetes, he treballat bé, però res més. I això m’ha permès després tindre tot el temps per a mi, cosa que d'una altra manera no

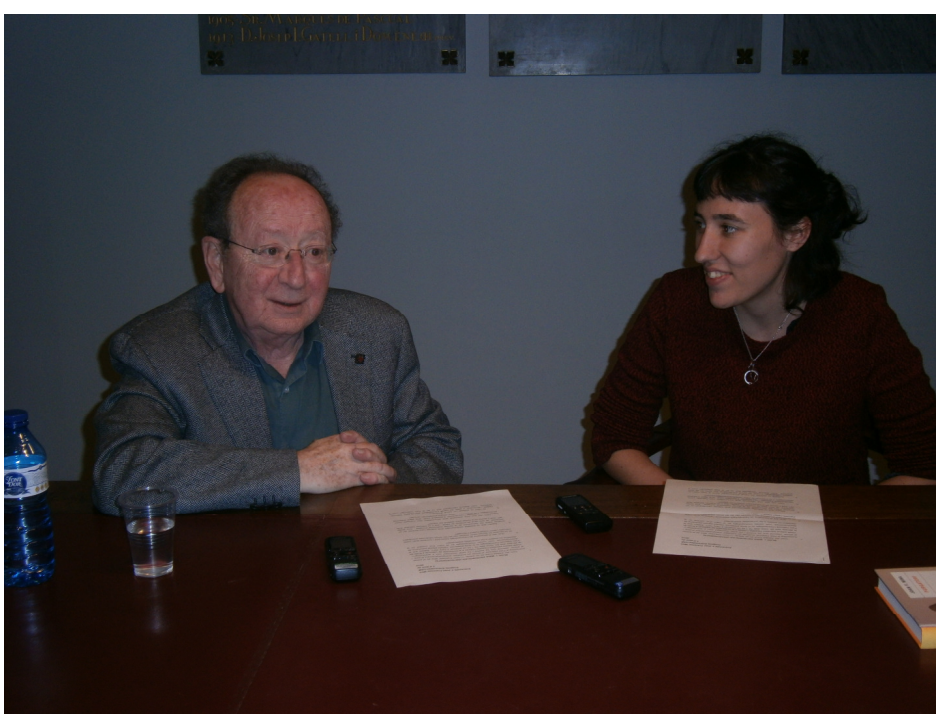

Joan Francesc Mira i una de les entrevistadores, Júlia Pagès (Foto: Montserrat Clua i Fainé) 


\section{perifèria}

Número 20 (1), juny 2015

www.periferia.name

hauria pogut fer. I el grec m'ha interessat sempre com a literatura, com a lector. M’ho he passat pipa tota la vida llegint Sòfocles, llegint Homer. I al final, després de jubilar-me, vaig dir: "Pos ara que he acabat, ara vaig a fer la meua traducció de l'Odissea". I m’ho he passat fantàsticament bé. Com m’ho vaig passar fantàsticament bé traduint la Divina Comèdia. Jo tinc una relació molt, molt llarga amb la cultura i la literatura italiana, des que tenia 19 o 20 anys. I després de 30 o 40 anys de relació amb una cultura i una llengua ja pots atrevir-te a traduir un clàssic, quan ja el tens molt interioritzat. D'això m'ha servit el grec, per a disfrutar-lo. Per a guanyar-me la vida i per passar-m'ho bé. Que són dues coses importants.

\section{P: Actualment tornaria a apostar una altra vegada per l'antropologia? En el context actual, si vostè hagués de tornar a estudiar.}

J. F Mira: Ai, no ho sé... li hauria de preguntar a la meua dona! [riures]. Mira, quan jo estava pensant si em quedava a Princeton o no m'hi quedava, jo estava allà amb la meua dona i teníem dos nanos de 8 i 10 anys. Llavors, quan jo estava pensant si em quede o no em quede, ella no se'n volia anar, perquè estava molt a gust allà. Allò és el paradís, és... No ho sé, mireu un dia pel Google, mireu Princeton i veureu que no es pareix a res. És una cosa, buff! És un paradís total, acadèmic i intel-lectual. Allò té la més gran densitat de premis Nobel per metre quadrat de tot el planeta Terra. És com un Harvard concentrat. Un dia parlant amb el departament d'admissions els hi vaig preguntar quina política d'admissions tenien i em van dir: "La primera qüestió que nosaltres fem és expedients acadèmics: el que no està en el primer $10 \%$ de la seua High School, d'entrada no cal que envie el currículum". I després fan entrevistes per veure les circumstàncies personals, etc. Sobre això, una de les normes que tenen és que els qui tenen diners paguen i paguen una pasta. I els qui no, tenen préstecs o 


\section{perifèria}

Número 20 (1), juny 2015

www.periferia.name

beques.

Doncs bé, quan estàvem a Princeton li van oferir un treball a la meua dona a la biblioteca, al departament de compres. La biblioteca té unes oficines grans i cada facultat o departament té uns responsables per a seleccionar i comprar llibres. I buscaven una persona que tinguera una llicenciatura universitària i que pogués dominar - o almenys controlar - les llengües romàniques: espanyol, català, francès, italià. I Pilar coneix català, espanyol i francès; I'italià també l'entén i amb el portuguès no hi ha cap problema. Li oferien la plaça de compradora de llibres de filologia romànica. La feina era mirar catàlegs, preguntar-te, interessar-te, preguntar als diferents professors de filologia romànica quin tipus de llibres els interessava, i tal. Doncs, aquest és el lloc de faena que li oferien. I ella estava encantada, ui!

\section{P: Última pregunta de ràdio i televisió del País Valencià...}

J.F. Mira: No, gràcies.

\section{P: No, gràcies?}

J.F. Mira: No, perquè jo ho sabeu. Què us he de dir? La meua opinió? La podeu improvisar, no cal que la diga. El problema és que, en aquestes coses si us done la meua opinió... ràpidament sortiria una llista d'insults, improperis... Però això no és una opinió. I a més a més em toca ser la víctima, en el moment actual com a president d'Acció Cultural del País Valencià...

\section{P: Però no li faran pagar la multa a vostè, no, d'Acció Cultural i tot això que ha passat...?}

J. F Mira: No, però quasi, saps... Això us ho explicaré un altre dia. Jo em vaig trobar en una circumstància en què m'oferien l'únic càrrec que m'han ofert en la vida: "Mira, vols el càrrec? Per tu". "Tu vols ser el capità d'un 


\section{perifèria}

Número 20 (1), juny 2015

www.periferia.name

barco, que s'està enfonsant, que està ple de forats, que té les veles trencades i que la bomba d'achicar l'aigua no funciona?" "Vinga va! Capità del barco." Fantàstic. Però deixem-ho aquí i anem a fer un cafè! I després me'n vaig corrents, que m'esperen els meus col-legues de la Secció de Filosofia i Ciències Socials de I'IEC per anar a l'aeroport, que demà fem unes sessions acadèmiques a l'Alguer.

Doncs, era l'última pregunta. Moltes gràcies!

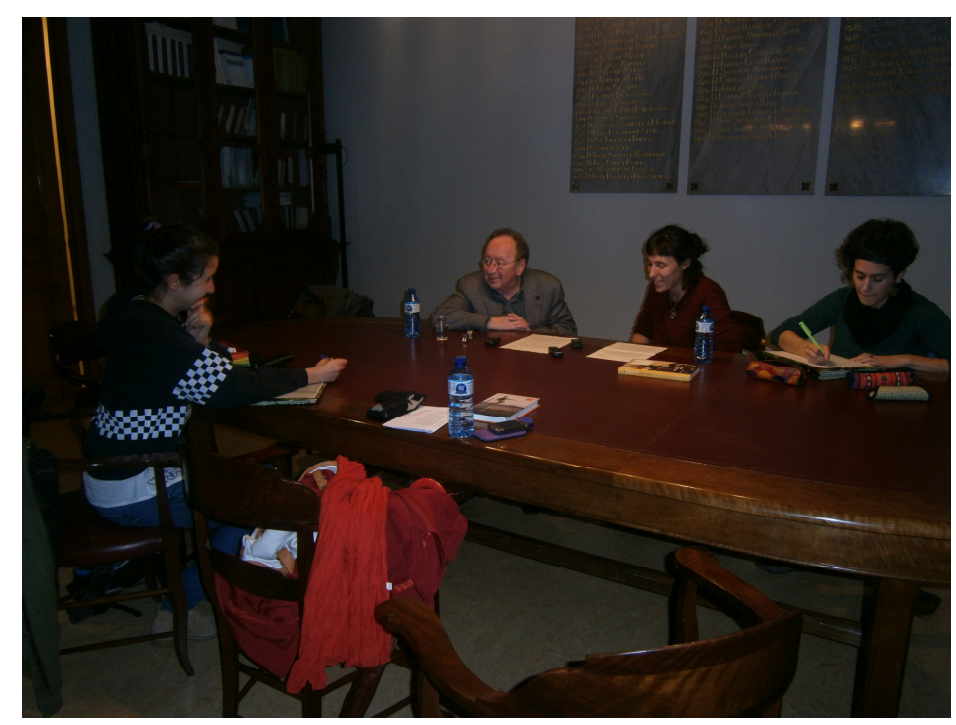

Joan Francesc Mira amb les tres entrevistadores: Júlia Morros, Júlia Paqès i Gemma Costa (Foto: Montserrat Clua i Fainé) 